\title{
Impact of preoperative endoscopy for predicting treatment response and prognosis in patients with gastric cancer after neoadjuvant chemotherapy
}

\section{(ㄷ)(우)}

Authors

Yoshiaki Shoji ${ }^{1}$, Souya Nunobe ${ }^{1}$, Naoki Nishie ${ }^{1}$, Shusuke Yagi ${ }^{1}$, Rie Makuuchi $^{1}$, Satoshi Ida ${ }^{1}$, Koshi Kumagai ${ }^{1}$, Manabu Ohashi $^{1}$, Akiyoshi Ishiyama², Toshiyuki Yoshio², Toshiaki Hirasawa², Junko Fujisaki², Takeshi Sano

Institutions

1 Department of Gastroenterological Surgery, Cancer Institute Hospital, Japanese Foundation for Cancer Research, Tokyo, Japan

2 Department of Gastroenterology, Cancer Institute Hospital, Japanese Foundation for Cancer Research, Tokyo, Japan

submitted 6.5.2021

accepted after revision $\quad 27.8 .2021$

\section{Bibliography}

Endosc Int Open 2022; 10: E62-E73

DOI 10.1055/a-1635-5855

ISSN 2364-3722

(C) 2022. The Author(s).

This is an open access article published by Thieme under the terms of the Creative Commons Attribution-NonDerivative-NonCommercial License, permitting copying and reproduction so long as the original work is given appropriate credit. Contents may not be used for commercial purposes, or adapted, remixed, transformed or built upon. (https://creativecommons.org/licenses/by-nc-nd/4.0/)

Georg Thieme Verlag KG, Rüdigerstraße 14,

70469 Stuttgart, Germany

Corresponding author

Souya Nunobe, MD, PhD, Department Gastroenterological Surgery, Cancer Institute Hospital, Japanese Foundation for Cancer Research, 3-8-31 Ariake, Koto-ku, Tokyo, 135-8550, Japan

Fax: +81-3-3570-0343

souya.nunobe@jfcr.or.jp

\section{ABSTRACT}

Background and study aims Response evaluation criteria in solid tumors (RECIST) have been the gold standard to preoperatively predict treatment response and prognosis in patients with gastric cancer (GC) after neoadjuvant chemotherapy (NAC); however, methods for patients without evaluable lesions by RECIST are not yet confirmed. The aim of this study was to assess the utility of preoperative endoscopy for predicting treatment response and prognosis in patients with GC after NAC.

Patients and methods This retrospective study included 105 patients with initially resectable GC who underwent NAC followed by surgical treatment. Preoperative factors for predicting treatment response and survival outcomes were analyzed.

Results The number of patients classified as responders using preoperative endoscopic assessment, RECIST, and postoperative pathological evaluation were 25 (23.8\%), 28 (26.7\%), and $18(17.1 \%)$, respectively. Forty-three patients $(41 \%)$ were classified as non-targeted disease only, and their treatment responses were not evaluable by RECIST. Multivariate analysis identified endoscopic response as an independent preoperative factor to predict postoperative histological treatment response (odds ratio $=4.556,95 \%$ $\mathrm{Cl}=1.169-17.746, P=0.029)$. Endoscopic treatment response was the only independent preoperative predictive factor for overall survival (OS) (hazard ratio $=0.419$, $95 \%$ confidence interval $(\mathrm{Cl})=0.206-0.849, P=0.016)$. Further, endoscopic treatment response was available for $33 \mathrm{pa}$ tients (76.7\%) with non-targeted disease only, which showed significantly different OS between endoscopic responders $(80.0 \%)$ and non-responders $(43.5 \%)(P=0.025)$.

Conclusions Endoscopic evaluation was an independent preoperative factor to predict treatment response and prognosis in patients with GC after NAC. Endoscopic assessment may be especially valuable for patients who could not be assessed by RECIST. 


\section{Introduction}

Treatment strategies for locally advanced gastric cancer (GC) have not been unified between Japan and Western countries [1]. Perioperative chemotherapy or postoperative chemotherapy plus radiation is the preferred treatment for localized GC in Western countries. In Japan, D2 gastrectomy followed by adjuvant chemotherapy is regarded as standard treatment. According to Japanese gastric cancer treatment guidelines, 2018 (5th edition) [2], neoadjuvant chemotherapy (NAC) is conditionally recommended for patients with a small number of enlarged lymph nodes at the no. $16 a 2$ or b1 region, and/or enlarged lymph nodes around the branches of the celiac artery, with no other non-curative factors. Clinical trials to demonstrate the superiority of perioperative chemotherapy over adjuvant chemotherapy for patients with clinical T3-4 N1-3 GC (JCOG1509) and extensive LN metastasis (JCOG1704) [3] are now ongoing.

There have been various attempts to predict treatment response and survival for patients with locally advanced GC treated with NAC following surgical resection, including those using diagnostic imaging [4-6], endoscopic examination [7-11], and liquid biopsy $[12,13]$. Diagnostic imaging, including fluorodeoxyglucose-positron emission tomography (PET-CT) and computed tomography (CT), is widely used in the clinics to assess the therapeutic effect of chemotherapy or radiation therapies in patients with solid tumors. Among them, response evaluation criteria in solid tumors (RECIST) using CT are among the most common criteria to classify treatment response; however, they may not always be suitable for GC because patients without enlarged lymph nodes (short axis $>15 \mathrm{~mm}$ ) would be defined as having "non-targeted disease only." Further, PET-CT appears to be less informative regarding early response in GC [14]. The efficacy of preoperative endoscopic evaluation using endoscopic ultrasound (EUS) and biopsy in patients after NAC is still controversial. EUS has a reduced ability to accurately determine the disease stage if performed after chemotherapy or radiation therapy, and biopsies performed after treatment may not detect the presence of residual disease accurately $[7,8]$.

In this study, we aimed to identify independent preoperative factors to predict treatment response and prognosis, using a well-defined NAC-treated GC cohort with a high follow-up rate. These factors may enable preoperative assessment of the therapeutic effect for patients without evaluable lesion by RECIST.

\section{Patients and methods}

\section{Patients}

All data in this retrospective study were collected from the GC database at the Cancer Institute Hospital, Tokyo, Japan. A total of 317 patients with primary GC underwent preoperative chemotherapy, followed by surgical treatment between January 2005 and December 2016. The patients who were excluded from the study had either undergone preoperative therapy for stage IV disease or had unresectable tumors that had invaded adjacent organs. The study included patients who were enrol-
Preoperative therapy for gastric cancer $\mathrm{n}=317$

Excluded

- Peritoneal dissemination

$\mathrm{n}=76$

- Liver metastasis

$\mathrm{n}=44$

- Ovarian metastasis

$\mathrm{n}=2$

- Splenic metastasis

- Distant lymph node metastasis

- Severe invasion to adjacent organs

- Portal vein thrombosis

$\mathrm{n}=1$

$\mathrm{n}=80$

$\mathrm{n}=8$

$\mathrm{n}=1$

Preoperative therapy for initially resectable locally advanced gastric cancergastric cancer $\mathrm{n}=105$

\begin{tabular}{|c|c|c|}
\hline$\downarrow$ & $\downarrow$ & $\downarrow$ \\
\hline $\begin{array}{l}\text { Lymph node } \\
\text { metastasis } \\
\mathrm{n}=84\end{array}$ & $\begin{array}{l}\text { Linitis plastica } \\
\text { and large } \\
\text { ulceroinvasive- } \\
\text { type tumors } \\
\mathrm{n}=13\end{array}$ & $\begin{array}{l}\text { Invasion to } \\
\text { adjacent } \\
\text { organs } \\
\mathrm{n}=8\end{array}$ \\
\hline
\end{tabular}

- Fig. 1 Flowchart of the patients enrolled in this study. A total of 105 patients with initially resectable locally advanced gastric cancer after neoadjuvant chemotherapy followed by surgery were included.

led in clinical trials testing NAC for linitis plastica and large ulceroinvasive-type tumors (JCOG0501 [15]), bulky nodal involvement around the celiac artery and its major branches (JCOG0405 [16]), and an independent clinical study testing NAC for advanced GC with node-positive disease. Finally, 105 patients who underwent NAC for initially resectable locally advanced GC (cT2-4, cN0-3, M0) followed by surgery were enrolled in this study ( $\triangleright$ Fig. 1). The Institutional Review Board of the Cancer Institute Hospital approved the study protocol (No. 2017-1199).

\section{Perioperative therapy, surgical procedure, and follow-up}

After neoadjuvant treatment, patients underwent either total gastrectomy or distal gastrectomy according to the size and location of the primary tumor [2]. Patients with all types of advanced proximal GC underwent splenectomy to dissect splenic hilar LNs, because all surgeries were performed before the results of the randomized controlled trial to evaluate splenectomy in total gastrectomy for proximal gastric carcinoma (JCOG0110) [17] were reported. Patients enrolled in the JCOG0405 study [16] underwent abdominal aortic lymph node dissection. Abdominal aortic lymph node with a long axis $>10$ $\mathrm{mm}$, as measured by CT before preoperative therapy, were considered as metastatic LNs [18], and were excluded from the study. 
- Table 1 JGCA response evaluation of primary tumor.

\begin{tabular}{l|l|l|}
$\begin{array}{l}\text { Complete response } \\
\text { (CR) }\end{array}$ & Disappearance of all tumor lesions and no diagnosis of carcinoma. Biopsy specimens are negative for carcinoma \\
\hline Partial response (PR) & $\begin{array}{l}\text { Measurable lesions: At least a } 30 \% \text { decrease in total size } \\
\text { Evaluable but not measurable lesions: Remarkable regression and flattening of a tumor, which roughly corresponds to at } \\
\text { least a } 50 \% \text { decrease in tumor size }\end{array}$ \\
\hline \begin{tabular}{l|l} 
Stable disease (SD) \\
Changes in tumor size or shape are less than PR, but are not progressive disease
\end{tabular} \\
\hline $\begin{array}{l}\text { Progressive disease } \\
\text { (PD) }\end{array}$ & $\begin{array}{l}\text { Increase in tumor size and/or worsening of the shape (20\% or more increase in measurable lesions), or new intragastric } \\
\text { lesions. }\end{array}$ \\
\hline JCCA, Japanese Gastric Cancer Association.
\end{tabular}

Based on the results of the Adjuvant Chemotherapy Trial of S-1 for Gastric Cancer (ACTS-GC)[19], adjuvant S-1 monotherapy was administered to eligible patients. The schedule, dose, and indication for S- 1 were according to the ACTS-GC protocol [19]. Some patients who entered clinical trials were administered S-1 plus oxaliplatin (SOX) or capecitabine plus oxaliplatin (XELOX) as adjuvant therapy. In the outpatient clinic, patients were evaluated for physical findings. They also underwent blood tests, including carcinoembryonic antigen (CEA) and carbohydrate antigen 19-9 (CA19-9) tumor markers, as well as semi-annual abdominal CT or ultrasonography.

\section{Preoperative and postoperative evaluations}

Endoscopic examination, CT imaging, and blood tests, including CEA and CA19-9, were performed before preoperative chemotherapy and 4 weeks after the final administration of neoadjuvant treatment. Clinicopathological outcomes, 3-year overall survival (OS), and relapse-free survival (RFS) were evaluated. Differentiated GC types included papillary and tubular adenocarcinomas. The undifferentiated types included poorly differentiated adenocarcinoma, signet ring cell carcinoma, and mucinous adenocarcinoma. Clinical responses to NAC measured using endoscopy and CT imaging were quantified based on the Japanese Gastric Cancer Association (JGCA) response evaluation of primary tumor [20] ( $>$ Table 1 ) and the revised RECIST guidelines version 1.1 [21], respectively. Representative images for endoscopic evaluations are shown in - Fig. 2. Endoscopic examinations were either performed or supervised by a BoardCertified Trainer of the Japan Gastroenterological Endoscopy Society. All assessment of the endoscopic images was performed preoperatively based on consensus manner of the four experienced endoscopists involved in this study (AI, TY, TH, and JF). Clinical responses evaluated by RECIST and endoscopy were presented and approved at the multidisciplinary tumor board of Gastroenterology Center, Cancer Institute Hospital, Japanese Foundation for Cancer Research, Tokyo, Japan. Patients with complete response (CR) or partial response (PR) were considered clinical responders. Patients with stable disease (SD) or progressive disease (PD) were considered clinical non-responders. Histological response to NAC was quantified based on the Japanese classification of gastric carcinoma, $3^{\text {rd }}$ English edition [20]. Patients with histological responses of grade 2 or above (viable tumor cells remaining in less than one-third of

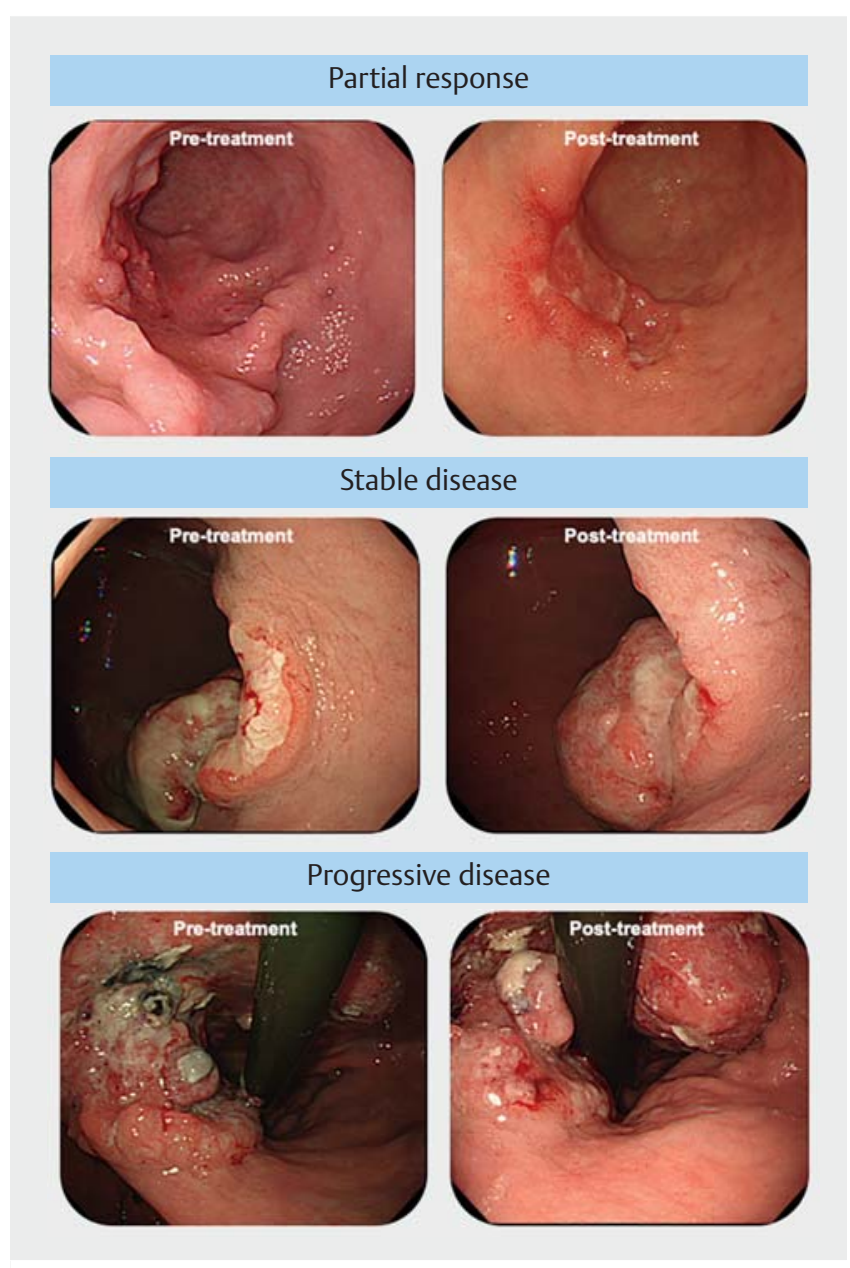

Fig. 2 Representative images for treatment response by endoscopic evaluation. Post-treatment endoscopic assessments were performed 4 weeks after the final administration of neoadjuvant treatment.

the tumor area) were considered histological responders. Patients with histological responses lower than grade 2 were considered histological non-responders. Clinical and pathological stages were classified according to the Japanese Classification of Gastric Carcinoma, 15 th Edition [22]. Clinical classification before and after preoperative chemotherapy, and pathological 
classifications after surgery were designated by cStage, ycStage, and ypStage, respectively.

\section{Statistical analyses}

Chi-square test and Fisher's exact test were used for statistical analyses. Spearman's rank-order correlation analysis was performed to test the association between clinical and pathological response. Multivariate analyses to identify the preoperative factors associated with pathologic response were conducted using a binary logistic regression model. OS and RFS were estimated using the Kaplan-Meier method and compared using the log-rank test. A multivariate Cox proportional hazards regression model was used to identify independent prognostic factors. Variables with $P<0.10$ in univariate analyses were subjected to the multivariate model. OS and RFS were calculated from the day of surgery. $P<0.05$ in all statistical tests were considered to represent statistically significant differences in all statistical tests. All statistical analyses were performed using the SPSS software program, ver. 25.0 (IBM Inc., Chicago, Illinois, United States). Unless otherwise indicated, data are presented as the median and range.

\section{Results}

\section{Patient background}

- Fig. 1 shows a flowchart for the patients in the present study. The study included 105 patients who underwent preoperative therapy for initially resectable locally advanced GC.

Most of the patients underwent NAC due to clinically nodepositive disease ( $n=88,83.8 \%$ ). Of them, 25 patients $(23.8 \%)$ had enlarged LNs around the branches of the celiac artery. Patients underwent S-1 plus cisplatin (SP) ( $n=90,85.7 \%)$, SOX ( $n=8,7.6 \%)$, epirubicin plus oxaliplatin plus capecitabine (EOX) $(n=2,1.9 \%)$, XELOX ( $n=2,1.9 \%), S-1$ alone $(n=1,1.0 \%)$, epirubicin plus cisplatin plus 5-fluorouracil (ECF) $(n=1,1.0 \%)$, or capecitabine plus cisplatin (XP) $(n=1,1.0 \%)$ prior to surgery. Most patients in this study were diagnosed as cStage III or above $(n=85,81.0 \%)$ and ycStage III or above $(n=87,82.9 \%)$. The median follow-up period was $40(0-155)$ months ( $\triangleright$ Table 2).

\section{Operative and postoperative outcomes}

$\mathrm{R} 0$ resection was achieved in 87 (82.9\%) patients. The reasons for $R 1$ and $R 2$ resection were cytology positive status $(n=9$, $8.6 \%)$, the presence of peritoneal dissemination $(n=4,3.8 \%)$, and a combination of these $(n=5,4.8 \%)$. Seventy-five $(71.4 \%)$ patients were diagnosed as ypStage III or above. Recurrent disease was observed in $44(41.9 \%)$ patients, which included hematogenous recurrence $(n=34,32.4 \%)$, peritoneal recurrence ( $n=16,15.2 \%)$, distant $L N$ recurrence $(n=14,13.3 \%)$, and local recurrence $(n=2,1.9 \%)$, which included overlapping cases ( $>$ Table 3).

\section{Treatment response}

- Table 4 summarizes clinical and histological responses to neoadjuvant treatment. Treatment response by RECIST was unevaluable for 43 of the patients (41\%) due to absence of targe-
- Table 2 Patient background data.

\begin{tabular}{|c|c|c|}
\hline \multicolumn{3}{|l|}{ Variables } \\
\hline Patients & 105 & \\
\hline Age, years & 64 & $(28-81)$ \\
\hline \multicolumn{3}{|l|}{$\operatorname{Sex}(\%)$} \\
\hline Male & 65 & $(61.9)$ \\
\hline Female & 40 & $(38.1)$ \\
\hline Proximal gastric cancer (\%) & 31 & $(29.5)$ \\
\hline Esophageal invasion (\%) & 19 & $(18.1)$ \\
\hline Duodenal invasion (\%) & 9 & $(8.6)$ \\
\hline \multicolumn{3}{|l|}{ Macroscopic types (\%) } \\
\hline Mass/ulcerative & 35 & $(33.3)$ \\
\hline Infiltrative & 59 & $(56.2)$ \\
\hline Unclassifiable & 4 & $(0.8)$ \\
\hline \multicolumn{3}{|l|}{ Reason for NAC (\%) } \\
\hline LN metastasis & 88 & $(83.8)$ \\
\hline Direct invasion to adjacent organs & 8 & $(7.6)$ \\
\hline $\begin{array}{l}\text { Linitis plastica and large ulceroinvasive- } \\
\text { type tumors }\end{array}$ & 9 & $(8.6)$ \\
\hline \multicolumn{3}{|l|}{ NAC regimen (\%) } \\
\hline SP & 90 & $(85.7)$ \\
\hline sox & 8 & $(7.6)$ \\
\hline Others & 7 & $(690.7)$ \\
\hline \multicolumn{3}{|l|}{ cStage (\%) } \\
\hline 1 & 0 & \\
\hline IIA & 2 & $(1.9)$ \\
\hline IIB & 9 & $(8.6)$ \\
\hline III & 77 & $(73.3)$ \\
\hline IVA & 8 & $(7.6)$ \\
\hline IVB & 0 & \\
\hline Unknown & 9 & $(8.6)$ \\
\hline \multicolumn{3}{|l|}{ ycStage (\%) } \\
\hline 1 & 1 & $(1.0)$ \\
\hline IIA & 2 & (1.9) \\
\hline ॥B & 13 & $(12.4)$ \\
\hline III & 81 & $(77.1)$ \\
\hline IVA & 6 & (5.7) \\
\hline IVB & 0 & \\
\hline Unknown & 2 & $(1.9)$ \\
\hline Follow-up period, months & 40 & $(0-155)$ \\
\hline $\begin{array}{l}\text { NAC, neoadjuvant chemotherapy; LN, lymph } \\
\text { SOX, S-1 plus oxaliplatin; cStage, clinical stag } \\
\text { ment; ycStage, clinical stage after preoperati }\end{array}$ & $\begin{array}{l}\text { SP, S- } \\
\text { ore pre } \\
\text { atmen }\end{array}$ & $\begin{array}{l}\text { Is cisplatin; } \\
\text { rative treat- }\end{array}$ \\
\hline
\end{tabular}


- Table 3 Operative, postoperative, and pathological outcomes.

\begin{tabular}{|c|c|c|}
\hline Variables & & \\
\hline \multicolumn{3}{|l|}{ Extent of gastric resection (\%) } \\
\hline Total gastrectomy & 63 & $(60)$ \\
\hline Distal gastrectomy & 40 & $(38.1)$ \\
\hline Non-resectional surgery & 2 & $(1.9)$ \\
\hline Combined resection of other organs (\%) & 19 & $(18.1)$ \\
\hline Splenectomy (\%) & 33 & $(31.4)$ \\
\hline Cytology positive (\%) & 15 & $(14.3)$ \\
\hline Peritoneal dissemination (\%) & 9 & $(8.6)$ \\
\hline Distant LN metastasis (\%) & 6 & $(5.7)$ \\
\hline Other distant metastasis (\%) & 2 & (1.9) \\
\hline R0 resection (\%) & 87 & $(82.9)$ \\
\hline \multicolumn{3}{|l|}{ ypStage (\%) } \\
\hline IA & 2 & (1.9) \\
\hline IB & 3 & (2.9) \\
\hline IIA & 10 & $(9.5)$ \\
\hline IIB & 13 & $(12.4)$ \\
\hline IIIA & 26 & $(24.8)$ \\
\hline IIIB & 17 & $(16.2)$ \\
\hline IIIC & 12 & $(11.4)$ \\
\hline IV & 20 & $(19.0)$ \\
\hline Unknown & 2 & (1.9) \\
\hline \multicolumn{3}{|l|}{ Histological classification (\%) } \\
\hline Differentiated adenocarcinoma & 74 & $(70.5)$ \\
\hline Undifferentiated adenocarcinoma & 26 & $(24.8)$ \\
\hline Others & 5 & $(4.8)$ \\
\hline Adjuvant therapy (\%) & 67 & $(63.8)$ \\
\hline Recurrence (\%) & 44 & $(41.9)$ \\
\hline
\end{tabular}

ted disease. The number of patients classified as clinical responders by endoscopic evaluation and RECIST was 25 (23.8\%, after excluding not evaluable patients; $30.5 \%)$ and 28 (26.7\%, after excluding not evaluable patients and patients with nontargeted disease only; $46.7 \%$ ), respectively. Pathological evaluation revealed that 18 (17.1\%, after excluding not evaluable patients; $22.2 \%$ ) patients achieved histological response of grade 2 or higher. Among them, two (1.9\%) patients achieved complete pathologic responses. Diagnostic accuracy of endoscopic evaluation and RECIST for histological response were $71.0 \%$ and $60.9 \%$, respectively. A weak correlation was observed between endoscopic assessment and pathological response (Spearman's rank correlation coefficient $\rho=0.301, P=0.017$ ), whereas there
- Table4 Treatment response.

\begin{tabular}{|c|c|c|}
\hline \multicolumn{3}{|l|}{ Variables } \\
\hline \multicolumn{3}{|c|}{ Clinical response by endoscopic evaluation (\%) } \\
\hline$C R$ & 0 & \\
\hline PR & 25 & (23.8) \\
\hline SD & 56 & $(53.3)$ \\
\hline PD & 1 & $(1.0)$ \\
\hline NE & 23 & (21.9) \\
\hline \multicolumn{3}{|l|}{ Clinical response by RECIST (\%) } \\
\hline Patients with targeted disease & 62 & $(59.0)$ \\
\hline$C R$ & 0 & \\
\hline PR & 28 & $(26.7)$ \\
\hline SD & 31 & (29.5) \\
\hline PD & 1 & $(1.0)$ \\
\hline NE & 2 & (1.9) \\
\hline Patients with non-targeted disease only & 43 & $(41.0)$ \\
\hline$C R$ & 0 & \\
\hline Non-CR/non-PD & 35 & (33.3) \\
\hline PD & 0 & \\
\hline NE & 8 & (7.6) \\
\hline \multicolumn{3}{|l|}{ Histological response (\%) } \\
\hline Grade 0 & 0 & \\
\hline Grade 1a & 47 & $(44.8)$ \\
\hline Grade 1b & 16 & (15.2) \\
\hline Grade 2a & 16 & (15.2) \\
\hline Grade 3 & 2 & (1.9) \\
\hline NE & 24 & (22.9) \\
\hline
\end{tabular}

was no association between RECIST and histological response (Spearman's rank correlation coefficient $\rho=0.255, P=0.087$ ).

\section{Preoperative factors associated with histological response}

The univariate analysis associated endoscopic clinical response with histological response $(\mathrm{OR}=4.431,95 \% \mathrm{Cl}=1.226-16.012$, $P=0.025)$. In the multivariate analysis of the three variables showing $P<0.1$ in the univariate analysis, endoscopic clinical response was an independent predictive factor for histological response $(\mathrm{OR}=4.556,95 \% \mathrm{Cl}=1.169-17.746, P=0.029)$ ( $>\mathrm{Ta}$ ble 5). 
- Table 5 Univariate and multivariate analyses of preoperative factors for histological response.

\begin{tabular}{|c|c|c|c|c|c|c|c|c|}
\hline Variables & $\begin{array}{l}\text { Non-re- } \\
\text { sponders }\end{array}$ & $\begin{array}{l}\text { Respon- } \\
\text { ders }\end{array}$ & & Univariate & & & Multivariate & \\
\hline & & & OR & $95 \% \mathrm{Cl}$ & $\begin{array}{l}P \text { value } \\
\text { value }\end{array}$ & OR & $95 \% \mathrm{Cl}$ & $\begin{array}{l}P \text { value } \\
\text { value }\end{array}$ \\
\hline Age, year & & & & & 0.789 & & & \\
\hline$<65$ & 34 & 11 & 1 & & & & & \\
\hline$\geq 65$ & 29 & 7 & 0.746 & $0.256-2.174$ & & & & \\
\hline Sex & & & & & 0.785 & & & \\
\hline Male & 39 & 10 & 1 & & & & & \\
\hline Female & 24 & 8 & 1.300 & $0.451-3.751$ & & & & \\
\hline CEA level after $A C$ & & & & & 0.784 & & & \\
\hline$\leq 5 \mathrm{ng} / \mathrm{mL}$ & 35 & 9 & 1 & & & & & \\
\hline$>5 \mathrm{ng} / \mathrm{mL}$ & 25 & 8 & 1.244 & $0.422-3.671$ & & & & \\
\hline CA19-9 level after NAC & & & & & 0.229 & & & \\
\hline$\leq 37 \mathrm{U} / \mathrm{mL}$ & 45 & 10 & 1 & & & & & \\
\hline$>37 \mathrm{U} / \mathrm{mL}$ & 15 & 7 & 2.100 & $0.679-6.494$ & & & & \\
\hline $\begin{array}{l}\text { Treatment response by endo- } \\
\text { scopic evaluation }\end{array}$ & & & & & 0.025 & & & 0.029 \\
\hline Non-responders & 36 & 5 & 1 & & & 1 & & \\
\hline Responders & 13 & 8 & 4.431 & $1.226-16.012$ & & 4.556 & $1.169-17.746$ & \\
\hline Treatment response by RECIST & & & & & 0.165 & & & \\
\hline Non-responders & 20 & 3 & 1 & & & 1 & & \\
\hline Responders & 15 & 8 & 3.556 & $0.804-15.717$ & & & & \\
\hline cStage & & & & & 0.079 & & & 0.170 \\
\hline I, II & 4 & 4 & 1 & & & 1 & & \\
\hline III & 52 & 13 & 0.250 & $0.055-1.135$ & & 0.484 & $0.172-1.365$ & \\
\hline ycStage & & & & & 0.063 & & & 0.755 \\
\hline I, II & 7 & 6 & 1 & & & 1 & & \\
\hline III & 55 & 12 & 0.255 & $0.072-0.894$ & & 0.841 & $0.283-2.490$ & \\
\hline Macroscopic types & & & & & 1.000 & & & \\
\hline Mass/ulcerative & 21 & 7 & 1 & & & & & \\
\hline Infiltrative & 31 & 10 & 0.968 & $0.318-2.974$ & & & & \\
\hline Tumor location & 33 & 11 & & & 1.000 & & & \\
\hline Proximal gastric cer & 24 & 7 & 0.875 & $0.296-2.58$ & & & & \\
\hline Others & 33 & 11 & 1 & & & & & \\
\hline
\end{tabular}

NAC, neoadjuvant chemotherapy. CEA, carcinoembryonic antigen. CA19-9, carbohydrate antigen 19-9. cStage, clinical stage before preoperative treatment. ycStage, clinical stage after preoperative treatment. OR, odds ratio. $\mathrm{Cl}$, confidence interval. 


\section{Preoperative predictors associated with prognosis}

Univariate analysis identified endoscopy-based clinical response as a significant prognostic factor for OS $(H R=0.402$, $95 \% \mathrm{Cl}=0.199-0.810, P=0.011)$. Of the two variables showing $P<0.1$ in univariate analysis, endoscopically evaluated clinical response was an independent prognostic factor for OS ( $\mathrm{HR}=$ $0.419,95 \% \mathrm{Cl}=0.206-0.849, P=0.016)$ in multivariate analysis ( $\triangleright$ Table 6). There were no preoperative factors predicting RFS in this study ( $>$ Table 7 ).

\section{Survival outcomes for clinical, and histological responders versus non-responders}

The 3-year OS rates were $80.0 \%$ for endoscopic responders and $48.6 \%$ for endoscopic non-responders, respectively $(P=0.008)$ ( Fig. 3a). The 3-year OS rates for histological responders and non-responders were $83.3 \%$ and $57.5 \%$, respectively $(P=0.041)$

( $\vee$ Fig. 3c). Clinical response evaluated by RECIST did not differentiate the 3-year OS rates for responders and non-responders ( $\downarrow$ Fig.3b). RFS analyses were limited to 66,51 , and 69 patients for endoscopic, RECIST, and histological response, respectively, because patients who could not achieve R0 resection were excluded. The 3-year RFS rates were not significantly different between responder and non-responders in any evaluation methods; however, 3-year RFS rates were relatively higher in the endoscopically evaluated clinical responders (65.2\%) than non-responders $(50.0 \%)(P=0.083)$ ( $\triangleright$ Fig.3d-f). Further, Survival analyses were performed for the patients who were not evaluable by RECIST due to the absence of targeted disease. Significant difference for the 3-year OS was observed between endoscopic responders (80.0\%) and non-responders (43.5\%) $(P=0.025)$ ( $\triangleright$ Fig.4a). There was no difference for the 3 -year RFS rates between the groups ( $\mathbf{F i g . 4 b}$ ). Nine patients were excluded from the RFS analysis due to non-curative resection.

\section{Discussion}

In this study, the clinical utility of preoperative endoscopic evaluation for patients with initially resectable locally advanced GC after NAC was demonstrated in a well-defined cohort with a high follow-up rate. Endoscopic treatment response was an independent preoperative factor to predict histological treatment response and OS based on multivariate analyses. Previous studies demonstrated the utility of endoscopy-based response evaluation for predicting survival in metastatic GC. Endoscopic and CT-based responses were equally associated with survival but with low correlation in cases evaluated by Park et al. [5], while Takahara et al. [10] reported that endoscopic evaluation was superior to CT-based assessment to predict survival. The results of our study are also supported by previous reports, which showed a relationship between endoscopic response and histological response or survival in a relatively small number of GC cases after neoadjuvant treatment $[9,11]$. To the best of our knowledge, this is the first study to analyze the relationship of multiple preoperative factors with histological treatment response and survival in patients with GC after NAC, including those patients who were not evaluable by RECIST, with sufficient number of cases for multivariate analyses.

Although endoscopic treatment response was significantly associated with histological response and OS, difference in RFS rates were not statistically significant between the endoscopic responders and non-responders. Major reason for this result may be the limited number of cases in the RFS analysis. Within the 105 cases included in this study, 18 patients (17.1\%) could not achieve R0 resection due to cytology positive status $(n=9$, $8.6 \%)$, the presence of peritoneal dissemination $(n=4,3.8 \%)$, and a combination of these $(n=5,4.8 \%)$. Therefore, the RFS analysis was limited to 87 patients, which may have affected the analysis. Another possible reason is the difference in response to postoperative treatment after recurrence between the groups. Endoscopic and histological responders may have achieved better response to chemotherapy for the recurrent disease compared to non-responders, therefore, significant differences may have been observed in the OS rates, but not in the RFS rates. Further, the follow-up period, which was limited to 40 months in this study, may also have affected the RFS analysis. In addition, postoperative variables such as histological treatment response and adjuvant treatment status were excluded in the survival analysis, since we intended to define a preoperative factor predicting patient survival. Those factors may affect patient survival and therefore, may be considered in future studies with a larger cohort and longer follow-up period.

As a result of the German FLOT4 study [23], perioperative chemotherapy with fluorouracil plus leucovorin, oxaliplatin, and docetaxel (FLOT) is now considered the new standard chemotherapy regimen for resectable GC in the Western countries, which showed the complete pathological regression rate of $15 \%$. In Japan, the standard treatment for locally advanced GC is surgery with the following postoperative adjuvant chemotherapy; however, NAC's efficacy has also been investigated for selected patients expected to have poor survival outcomes [24]. Several trials have suggested that increasing the number of chemotherapy cycles leads to a higher pathologic response rate in esophageal cancer and GC [25-27]. These results suggest that endoscopic assessment of the treatment response may enable patient selection for those who need modifications of the preoperative therapy, and additional cycles of neoadjuvant therapy may be administered for endoscopic non-responders to improve treatment response and achieve better survival outcomes. In addition, more aggressive preoperative combination therapy, such as FLOT or triplet therapy containing docetaxel, oxaliplatin, and S-1 (DOS), as administered in the JCOG1704 study [3], may improve outcomes for endoscopic non-responders. Result of JCOG1704 study and further clinical trials for NAC is awaited. In addition to the RECIST, endoscopic treatment responses should also be evaluated in the future trials.

Adjuvant chemotherapy with a doublet regimen containing S-1 plus docetaxel (DS) is preferred over S-1 monotherapy for pStage III GC according to the results of the JACCRO GC-07 study [28] in Japan. Because we have shown that endoscopic non-responders had worse survival outcomes than endoscopic 
- Table 6 Univariate and multivariate analyses of preoperative factors for overall survival.

\begin{tabular}{|c|c|c|c|c|c|c|}
\hline \multirow[t]{2}{*}{ Variables } & \multicolumn{3}{|c|}{ Univariate } & \multicolumn{3}{|c|}{ Multivariate } \\
\hline & HR & $95 \% \mathrm{Cl}$ & $P$ value & HR & $95 \% \mathrm{Cl}$ & $P$ value \\
\hline Age, year & & & 0.627 & & & \\
\hline$<65$ & 1 & & & & & \\
\hline$\geq 65$ & 0.881 & $0.529-1.467$ & & & & \\
\hline Sex & & & 0.115 & & & \\
\hline Male & 1 & & & & & \\
\hline Female & 0.645 & $0.374-1.113$ & & & & \\
\hline NAC courses & & & 0.514 & & & \\
\hline 1 & 1 & & & & & \\
\hline$\geq 2$ & 1.187 & $0.710-1.985$ & & & & \\
\hline CEA level after NAC & & & 0.594 & & & \\
\hline$\leq 5 \mathrm{ng} / \mathrm{mL}$ & 1 & & & & & \\
\hline$>5 \mathrm{ng} / \mathrm{mL}$ & 1.153 & $0.683-1.948$ & & & & \\
\hline CA19-9 level, after NAC & & & 0.514 & & & \\
\hline$\leq 37 \mathrm{U} / \mathrm{mL}$ & 1 & & & & & \\
\hline$>37 \mathrm{U} / \mathrm{mL}$ & 1.210 & $0.683-2.145$ & & & & \\
\hline Treatment response by endoscopic evaluation & & & 0.011 & & & 0.016 \\
\hline Non-responders & 1 & & & 1 & & \\
\hline Responders & 0.402 & $0.199-0.810$ & & 0.419 & $0.206-0.849$ & \\
\hline Treatment response by RECIST & & & 0.131 & & & \\
\hline Non-responders & 1 & & & & & \\
\hline Responders & 0.579 & $0.285-1.177$ & & & & \\
\hline cStage & & & 0.579 & & & \\
\hline I, II & 1 & & & & & \\
\hline III & 0.894 & $0.600-1.330$ & & & & \\
\hline ycStage & & & 0.217 & & & \\
\hline I, II & 1 & & & & & \\
\hline III & 1.283 & $0.864-1.904$ & & & & \\
\hline Macroscopic types & & & 0.082 & & & 0.133 \\
\hline Mass/ulcerative & 1 & & & 1 & & \\
\hline Infiltrative & 1.696 & $0.934-3.078$ & & 1.610 & $0.865-2.994$ & \\
\hline Tumor location & & & 0.944 & & & \\
\hline Proximal gastric cancer & 1.019 & $0.598-1.737$ & & & & \\
\hline Others & 1 & & & & & \\
\hline
\end{tabular}

NAC, neoadjuvant chemotherapy; CEA, carcinoembryonic antigen; CA19-9, carbohydrate antigen 19-9; cStage, clinical stage before preoperative treatment; ycStage, clinical stage after preoperative Treatment; $\mathrm{HR}$, hazard ratio; $\mathrm{Cl}$, confidence interval. 
- Table 7 Univariate analyses of preoperative factors for relapse-free survival.

\begin{tabular}{|c|c|c|c|}
\hline Variables & HR & $95 \% \mathrm{Cl}$ & $P$ value \\
\hline Age, year & & & 0.337 \\
\hline$<65$ & 1 & & \\
\hline$\geq 65$ & 0.745 & $0.408-1.359$ & \\
\hline Sex & & & 0.330 \\
\hline Male & 1 & & \\
\hline Female & 0.739 & $0.403-1.357$ & \\
\hline NAC courses & & & 0.201 \\
\hline 1 & 1 & & \\
\hline$\geq 2$ & 1.493 & $0.807-2.762$ & \\
\hline CEA level after NAC & & & 0.849 \\
\hline$\leq 5 \mathrm{ng} / \mathrm{mL}$ & 1 & & \\
\hline$>5 \mathrm{ng} / \mathrm{mL}$ & 0.941 & $0.503-1.762$ & \\
\hline CA19-9 level, after NAC & & & 0.715 \\
\hline$\leq 37 \mathrm{U} / \mathrm{mL}$ & 1 & & \\
\hline$>37 \mathrm{U} / \mathrm{mL}$ & 0.880 & $0.444-1.746$ & \\
\hline $\begin{array}{l}\text { Treatment response by } \\
\text { endoscopic evaluation }\end{array}$ & & & 0.093 \\
\hline Non-responders & 1 & & \\
\hline Responders & 0.505 & $0.227-1.120$ & \\
\hline $\begin{array}{l}\text { Treatment response by RE- } \\
\text { CIST }\end{array}$ & & & 0.757 \\
\hline Non-responders & 1 & & \\
\hline Responders & 0.883 & $0.403-1.939$ & \\
\hline cStage & & & 0.261 \\
\hline I, II & 1 & & \\
\hline III & 0.777 & $0.501-1.206$ & \\
\hline ycStage & & & 0.738 \\
\hline I, II & 1 & & \\
\hline III & 1.074 & $0.717-1.610$ & \\
\hline Macroscopic types & & & 0.867 \\
\hline Mass/ulcerative & 1 & & \\
\hline Infiltrative & 1.059 & $0.544-2.059$ & \\
\hline Tumor location & & & 0.933 \\
\hline Proximal gastric cancer & 0.973 & $0.517-1.330$ & \\
\hline Others & 1 & & \\
\hline \multicolumn{4}{|c|}{$\begin{array}{l}\text { NAC, neoadjuvant chemotherapy; CEA, carcinoembryonic antigen; CA19-9, } \\
\text { carbohydrate antigen 19-9; cStage, clinical stage before preoperative } \\
\text { treatment; ycStage, clinical stage after preoperative treatment. }\end{array}$} \\
\hline
\end{tabular}
FLOT, and XELOX [29], or immunotherapeutic strategies may be considered for these patients. Further, early initiation and completion of adjuvant therapy improve prognosis in several types of cancers, including GC [30,31]. Extensive surgery may be avoided in endoscopic non-responders to enable early initiation and completion of postoperative treatment.

RECIST is the most common criterion to classify treatment response in solid tumors. However, RECIST failed to predict postoperative survival in this study. The primary lesion in hollow-organ cancers, including GC, is defined as "non-targeted lesion" by RECIST. Thus, RECIST may not be suitable for a detailed evaluation of treatment response in primary node-negative diseases. In this study, 43 patients (41.0\%), including 11 cases $(10.5 \%)$ of linitis plastica and large ulceroinvasive-type tumors, had non-targeted disease only. Endoscopic preoperative response evaluation was available for 33 of these patients, and was a significant factor differentiating 3-year OS rates. Endoscopic evaluation seems especially valuable for patients with non-targeted disease only. Another reason RECIST failed to predict treatment response may be the diagnostic accuracy of detecting lymph node metastasis using CT. In this study, 13 of 88 patients ( $14.8 \%$ ) diagnosed as having clinically node-positive disease after neoadjuvant therapy had no pathological lymph node metastasis. This result suggests that size of the lymph node may not always reflect nodal involvement or treatment response, as has been discussed in previous publications $[32,33]$. Although, CT is still a useful and less-invasive inspection to evaluate clinical response in both neoadjuvant and definitive settings in most solid tumors. Therefore, RECIST should always be considered to assess treatment responses for patients with targeted disease.

Some limitations should be addressed. The first is the limited number of cases in this study. However, the 105 patients with a high follow-up rate included in this study should be valuable, because endoscopy repeated before and after neoadjuvant treatment is not routinely performed in Western countries [11], and NAC is not the standard of care for locally advanced GC in Japan. Within the 105 patients included in this study, clinical response by RECIST was not evaluable for 43 patients (41\%) due to the absence of targeted disease. To make an accurate comparison for the clinical utility of endoscopic and RECIST assessment, more patients with targeted disease should be evaluated in future studies. However, many patients with GC indicated to NAC have non-targeted disease only, therefore the main purpose of this study was to identify preoperative factors to predict treatment response and survival for patients who are unevaluable by RECIST. In this regard, endoscopic evaluation is a valuable tool as discussed above. Endoscopic, RECIST, and Histological response were not evaluable in this study for 23 (21.9\%), 10 (9.5\%), and 24 patients (22.9\%), respectively, and may also have affected the results of this study. These are due to either missing pretreatment or preoperative examination, or untreated data at the point of data collection. All data including clinical and histological responses were collected prospectively in order to avoid observation bias. The second is the relatively subjective nature of endoscopic evaluation. Although the 


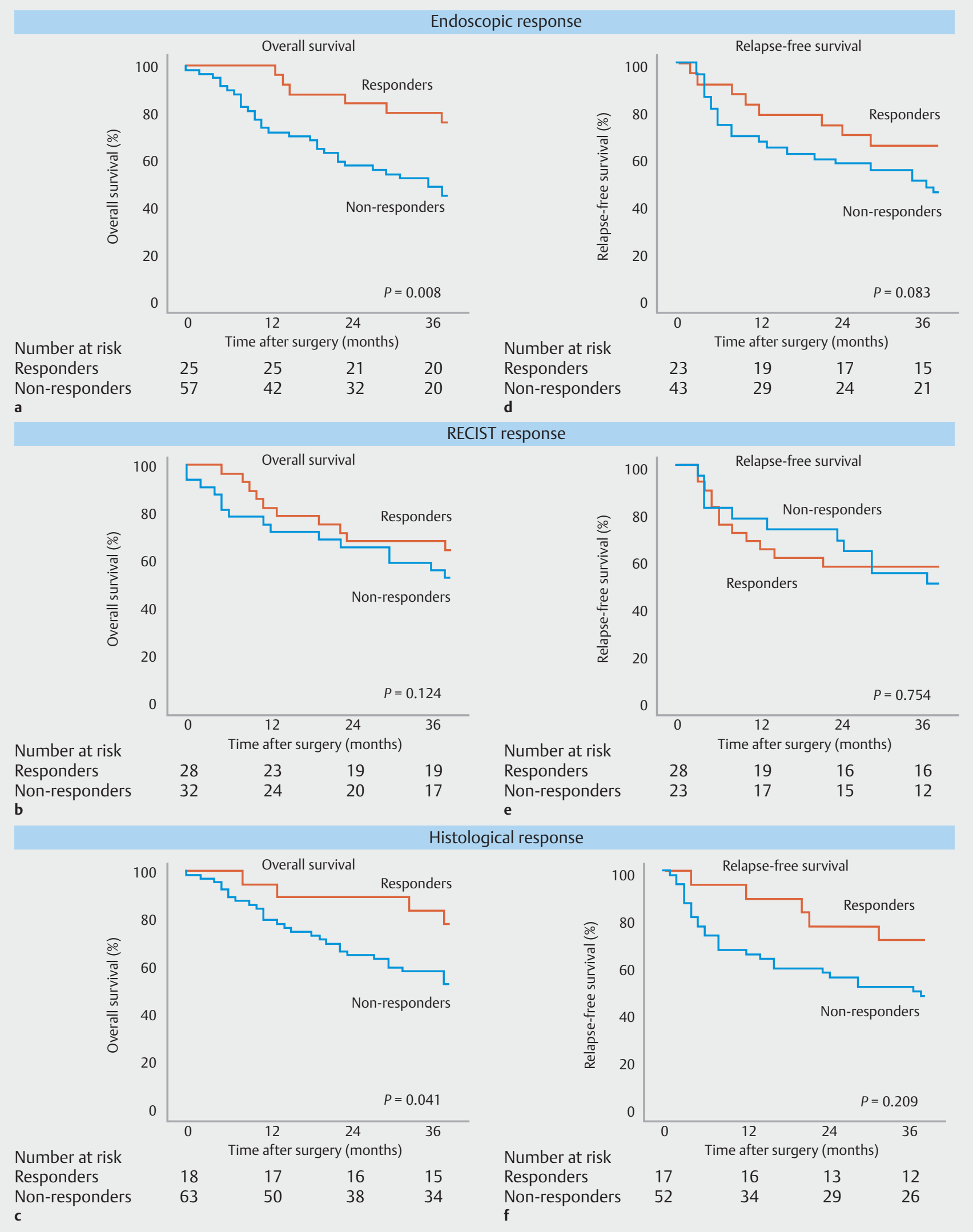

- Fig. 3 Survival outcomes for endoscopic, RECIST, and histological response. a, c The 3-year overall survival (OS) rates were significantly higher in endoscopic and histological responders than non-responders $(P=0.008$ and 0.041$)$. b There were no significant differences in 3 -year OS rates between RECIST responders and non-responders. d, e, $\mathbf{f}$ The 3-year relapse-free survival (RFS) rates were not significantly different between responders and non-responders in any evaluation method; however, 3-year RFS rates were relatively higher in endoscopic responders than non-responders $(P=0.083)$. 


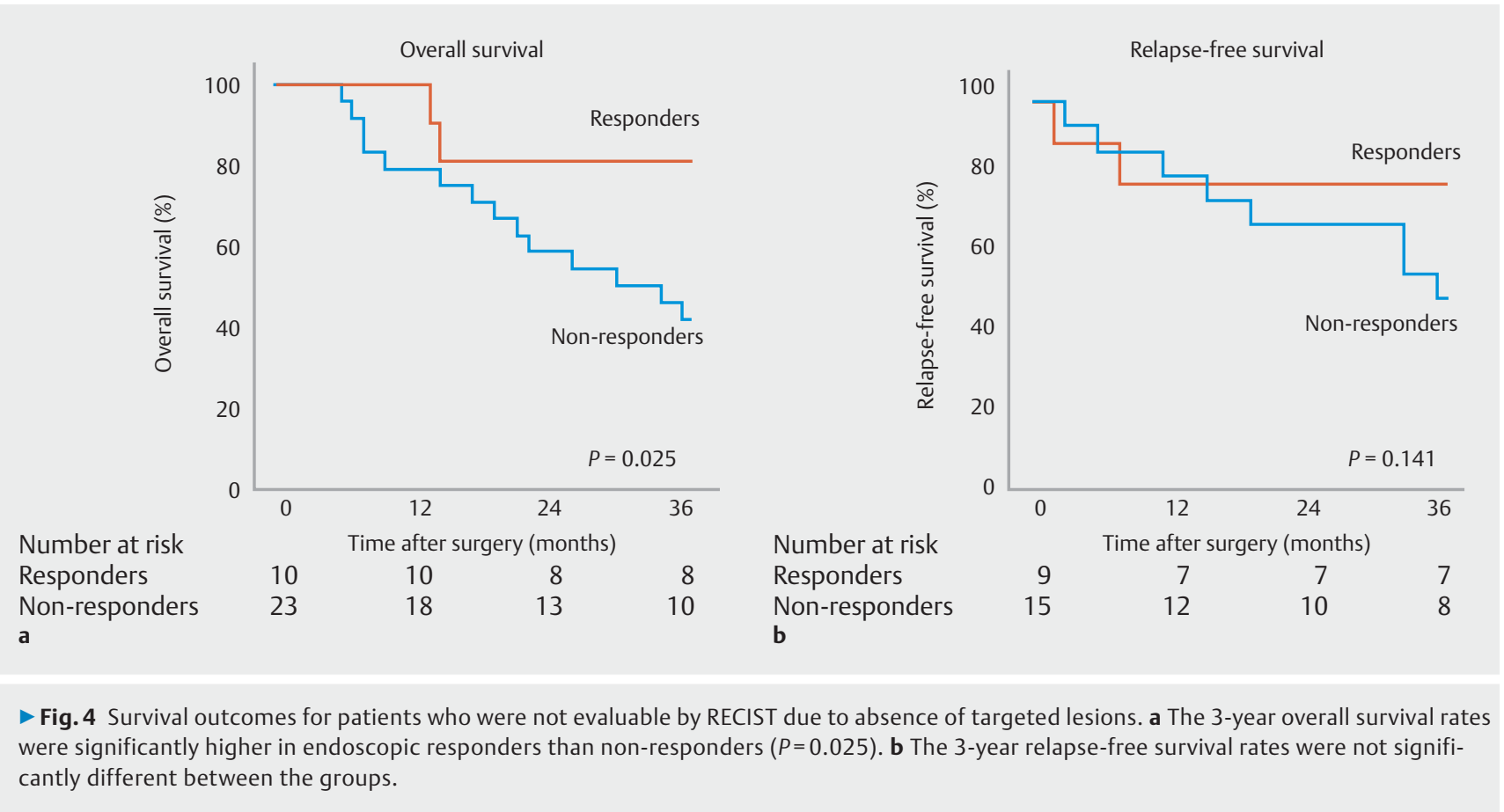

endoscopic examination was either performed or supervised by experienced endoscopists, all assessment of the endoscopic images was performed preoperatively based on consensus manner of the four experienced endoscopists involved in this study, the clinical responses were defined at the multidisciplinary tumor board, and endoscopic treatment response was quantified based on the JGCA response evaluation of primary tumor which is one of the most commonly used criteria for evaluating endoscopic treatment effect, the level of experience of the investigator in neoadjuvant-treated GC remains a factor. Endoscopy is currently the only method that allows for the preoperative assessment of the primary tumor. Novel technologies for virtual endoscopy $[34,35]$ may allow for more objective evaluation. The third is the retrospective nature of the analysis. In order to clarify the clinical utility of preoperative endoscopic evaluation, timing to assess the clinical response should be carefully determined in future prospective studies. In addition, this study did not include patients who did not undergo surgical treatment because of clinically apparent distant metastasis or local failure during NAC. Although this represents a relatively small population, to grasp the entire aspect, these patients should be included and evaluated for prognosis in future studies. In addition, because the results of this study indicate the clinical importance of endoscopic assessment for patients after preoperative treatment, marginally-resectable GC after NAC and initially non-resectable GC who underwent definitive chemotherapy followed by conversion surgery may be included and analyzed in future studies.

\section{Conclusions}

Endoscopic evaluation of treatment response was an independent factor for predicting histological treatment response and survival in patients with locally advanced GC after NAC. Preoperative endoscopy may allow treatment response evaluation and survival prediction for patients without evaluable lesions, and should be considered for those receiving preoperative treatment.

\section{Competing interests}

The authors declare that they have no conflict of interest.

\section{References}

[1] Terashima M, Yoshikawa T, Boku N et al. Current status of perioperative chemotherapy for locally advanced gastric cancer and JCOG perspectives. Jpn J Clin Oncol 2020; 50: 528-534

[2] Japanese Gastric Cancer Association. Japanese gastric cancer treatment guidelines 2018 (5th edition). Gastric Cancer 2021: doi:10.1007/s10120-020-01042-y (Epub 2020 Feb 14)

[3] Sato Y, Kurokawa Y, Doki Y et al. A Phase II study of preoperative chemotherapy with docetaxel, oxaliplatin and S-1 in gastric cancer with extensive lymph node metastasis (JCOG1704). Future Oncol 2020; 16: 31-38

[4] Beer AJ, Wieder HA, Lordick F et al. Adenocarcinomas of esophagogastric junction: multi-detector row $C T$ to evaluate early response to neoadjuvant chemotherapy. Radiology 2006; 239: 472-480

[5] Park SR, Choi IJ, Kim CG et al. Use of a combination of computed tomography and endoscopy to assess the response to 5 -fluorouracil/ cisplatin and predict survival in gastric cancer. J Gastroenterol 2006; 41: 339-346 
[6] Ott K, Fink U, Becker $\mathrm{K}$ et al. Prediction of response to preoperative chemotherapy in gastric carcinoma by metabolic imaging: results of a prospective trial. J Clin Oncol 2003; 21: 4604-4610

[7] Park SR, Lee JS, Kim CG et al. Endoscopic ultrasound and computed tomography in restaging and predicting prognosis after neoadjuvant chemotherapy in patients with locally advanced gastric cancer. Cancer 2008; 112: 2368-2376

[8] Sarkaria IS, Rizk NP, Bains MS et al. Post-treatment endoscopic biopsy is a poor-predictor of pathologic response in patients undergoing chemoradiation therapy for esophageal cancer. Ann Surg 2009; 249: 764-767

[9] Sugawara N, Ota K, Terazawa T et al. Endoscopic evaluation of neoadjuvant chemotherapeutic efficacy in gastric cancer before gastrectomy might be as useful as histological assessment after gastrectomy. Digestion 2020; 101: 466-472 doi:10.1159/000500907 (Epub 2019 Jun 28)

[10] Tahara T, Shibata T, Okubo M et al. Evaluations of primary lesions by endoscopy clearly distinguishes prognosis in patients with gastric cancer who receive chemotherapy. PLoS One 2017; 12: e0173663

[11] Heger $U$, Bader F, Lordick F et al. Interim endoscopy results during neoadjuvant therapy for gastric cancer correlate with histopathological response and prognosis. Gastric Cancer 2014; 17: 478-488

[12] Kato S, Okamura R, Baumgartner JM et al. Analysis of circulating tumor DNA and clinical correlates in patients with esophageal, gastroesophageal junction, and gastric adenocarcinoma. Clin Cancer Res 2018; 24: 6248-6256

[13] Willis ], Lefterova MI, Artyomenko A et al. Validation of microsatellite instability detection using a comprehensive plasma-based genotyping panel. Clin Cancer Res 2019; 25: 7035-7045

[14] Ott K, Herrmann K, Schuster T et al. Molecular imaging of proliferation and glucose utilization: utility for monitoring response and prognosis after neoadjuvant therapy in locally advanced gastric cancer. Ann Surg Oncol 2011; 18: 3316-3323

[15] Terashima M, Iwasaki Y, Mizusawa J et al. Randomized phase III trial of gastrectomy with or without neoadjuvant S-1 plus cisplatin for type 4 or large type 3 gastric cancer, the short-term safety and surgical results: Japan Clinical Oncology Group Study (JCOG0501). Gastric Cancer 2019; 22: 1044-1052

[16] Tsuburaya A, Mizusawa J, Tanaka Y et al. Neoadjuvant chemotherapy with S-1 and cisplatin followed by D2 gastrectomy with para-aortic lymph node dissection for gastric cancer with extensive lymph node metastasis. Br J Surg 2014; 101: 653-660

[17] Sano T, Sasako M, Mizusawa J et al. Randomized controlled trial to evaluate splenectomy in total gastrectomy for proximal gastric carcinoma. Ann Surg 2017; 265: 277-283

[18] Monig SP, Zirbes TK, Schroder W et al. Staging of gastric cancer: correlation of lymph node size and metastatic infiltration. AJR Am J Roentgenol 1999; 173: 365-367

[19] Sakuramoto S, Sasako M, Yamaguchi T et al. Adjuvant chemotherapy for gastric cancer with S-1, an oral fluoropyrimidine. N Engl J Med 2007; 357: 1810-1820

[20] Japanese Gastric Cancer Association. Japanese classification of gastric carcinoma: 3rd English edition. Gastric Cancer 2011; 14: 101-112

[21] Eisenhauer EA, Therasse P, Bogaerts J et al. New response evaluation criteria in solid tumours: revised RECIST guideline (version 1.1). Eur J Cancer 2009; 45: 228-247
[22] Komatsu S, Otsuji E. Essential updates 2017/2018: Recent topics in the treatment and research of gastric cancer in Japan. Ann Gastroenterol Surg 2019; 3: 581-591

[23] Al-Batran SE, Homann N, Pauligk C et al. Perioperative chemotherapy with fluorouracil plus leucovorin, oxaliplatin, and docetaxel versus fluorouracil or capecitabine plus cisplatin and epirubicin for locally advanced, resectable gastric or gastro-oesophageal junction adenocarcinoma (FLOT4): a randomised, phase 2/3 trial. Lancet 2019; 393: 1948-1957

[24] Tokunaga M, Sato Y, Nakagawa M et al. Perioperative chemotherapy for locally advanced gastric cancer in Japan: current and future perspectives. Surg Today 2020; 50: 30-37

[25] Alderson D, Cunningham D, Nankivell M et al. Neoadjuvant cisplatin and fluorouracil versus epirubicin, cisplatin, and capecitabine followed by resection in patients with oesophageal adenocarcinoma (UK MRC OE05): an open-label, randomised phase 3 trial. Lancet Oncol 2017; 18: 1249-1260

[26] Ajani JA, Xiao L, Roth JA et al. A phase II randomized trial of induction chemotherapy versus no induction chemotherapy followed by preoperative chemoradiation in patients with esophageal cancer. Ann Oncol 2013; 24: 2844-2849

[27] Sumpter K, Harper-Wynne C, Cunningham D et al. Report of two protocol planned interim analyses in a randomised multicentre phase III study comparing capecitabine with fluorouracil and oxaliplatin with cisplatin in patients with advanced oesophagogastric cancer receiving ECF. Br J Cancer 2005; 92: 1976-1983

[28] Yoshida K, Kodera Y, Kochi M et al. Addition of docetaxel to oral fluoropyrimidine improves efficacy in patients with stage III gastric cancer: interim analysis of JACCRO GC-07, a randomized controlled trial. J Clin Oncol 2019; 37: 1296-1304

[29] Kim IH, Park SS, Lee CM et al. Efficacy of adjuvant S-1 versus xelox chemotherapy for patients with gastric cancer after D2 lymph node dissection: a retrospective, multi-center observational study. Ann Surg Oncol 2018; 25: 1176-1183

[30] Park HS, Jung M, Kim HS et al. Proper timing of adjuvant chemotherapy affects survival in patients with stage 2 and 3 gastric cancer. Ann Surg Oncol 2015; 22: 224-231

[31] Yoshikawa T, Terashima M, Mizusawa J et al. Four courses versus eight courses of adjuvant S-1 for patients with stage II gastric cancer (JCOG1104 [OPAS-1]): an open-label, phase 3, non-inferiority, randomised trial. Lancet Gastroenterol Hepatol 2019; 4: 208-216

[32] Kim DJ, Kim W. Is lymph node size a reliable factor for estimating lymph node metastasis in early gastric cancer? J Gastric Cancer 2018; 18: $20-29$

[33] Fukagawa T, Katai H, Mizusawa J et al. A prospective multi-institutional validity study to evaluate the accuracy of clinical diagnosis of pathological stage III gastric cancer (JCOG1302A). Gastric Cancer 2018; 21: 68-73

[34] Furukawa K, Miyahara R, Itoh A et al. Diagnosis of the invasion depth of gastric cancer using MDCT with virtual gastroscopy: comparison with staging with endoscopic ultrasound. AJR Am J Roentgenol 2011; 197: 867-875

[35] Moschetta M, Scardapane A, Telegrafo M et al. Differential diagnosis between benign and malignant ulcers: 320-row CT virtual gastroscopy. Abdom Imaging 2012; 37: 1066-1073 